\title{
Chemopreventive effect of fermented brown rice and rice bran (FBRA) on the inflammation-related colorectal carcinogenesis in $A p c^{\mathrm{Min} /+}$ mice
}

\author{
SUPHOT PHUTTHAPHADOONG ${ }^{1,2}$, YASUHIRO YAMADA ${ }^{1}$, AKIHIRO HIRATA $^{3}$, \\ HIROYUKI TOMITA $^{1}$, AKIRA HARA ${ }^{1}$, PORNNGARM LIMTRAKUL ${ }^{2}$, \\ TERUAKI IWASAKI ${ }^{4}$, HIROSHI KOBAYASHI ${ }^{5}$ and HIDEKI MORI ${ }^{1}$
}

\author{
${ }^{1}$ Department of Tumor Pathology, Gifu University Graduate School of Medicine, 1-1 Yanagido, \\ Gifu 501-1194, Japan; ²Department of Biochemistry, Faculty of Medicine, Chiang Mai University, \\ Chiang Mai 50200, Thailand; ${ }^{3}$ Division of Animal Experiment, Life Science Research Center, \\ Gifu University, 1-1 Yanagido, Gifu 501-1193; ${ }^{4}$ Genmai Koso Co., Ltd., Nishi 1-chome, Kita 12-jo, \\ Kita-ku, Sapporo 001-0012; ${ }^{5}$ Sapporo Cancer Seminar, 6 Odori-Nishi, Chuo-ku, Sapporo 064-0820, Japan
}

Received July 17, 2009; Accepted September 1, 2009

DOI: 10.3892/or_00000605

\begin{abstract}
Our previous study revealed that fermented brown rice and rice bran (FBRA) suppresses rat colorectal carcinogenesis induced by azoxymethane, the colon-specific carcinogen. In the present study, we examined the suppressive effect of FBRA on colon carcinogenesis in $A p c^{\mathrm{Min} /+}$ mouse, a mouse model for human familial adenomatous polyposis. In contrast to previous findings with the carcinogen-induced model, administration of 5 and 10\% FBRA had no effect on the tumor development in the colon of $A p c^{\mathrm{Min} /+}$ mice, suggesting that the modifying effects of FBRA on colorectal carcinogenesis are different depending on rodent models for colorectal carcinogenesis. However, when FBRA is administrated in dextran sodium sulfate (DSS)-exposed $A p c^{\mathrm{Min} /+}$ mouse, a mouse model for the inflammation-related colorectal carcinogenesis, FBRA significantly suppressed the multiplicity of colon tumors in comparison with control diet group. FBRA administration suppressed the cell proliferative index, which is accompanied by the significantly decreased mRNA expressions of Cox 2 and iNos in colonic mucosa exposed to DSS ( $\mathrm{p}<0.04$ and 0.02 , respectively). These findings indicate that FBRA has chemopreventive effects specifically against inflammation-related tumorigenesis in the colon. Our findings also suggest that anti-inflammatory activity is one of the underlying mechanisms by which FBRA suppresses tumorigenesis in the colon.
\end{abstract}

Correspondence to: Dr Yasuhiro Yamada, Department of Tumor Pathology, Gifu University Graduate School of Medicine, 1-1 Yanagido, Gifu 501-1194, Japan

E-mail: y-yamada@gifu-u.ac.jp

Key words: inflammation, colorectal carcinogenesis

\section{Introduction}

Inflammation has been recognized as a major factor in the pathogenesis of several common diseases, including cancer. Patients with inflammatory bowel disease (IBD), including ulcerative colitis (UC) and Crohn's disease (CD), have an increased risk of colorectal cancer (CRC) (1). The molecular alterations in colitis-associated CRC are thought to be similar to the adenoma-carcinoma sequence in sporadic colorectal carcinoma, including the loss of function of the $A P C$, p53 and $K$-ras gene. However, it is suggested that the timing and frequency of these genetic alterations in colitis-associated CRC occur differently from sporadic colorectal carcinomas (2-4).

Animal models of experimental colitis have been developed and are often used to evaluate new treatments for IBD (4). As the onset of inflammation is immediate and the procedure is relatively straightforward, chemically induced models of intestinal inflammation, such as the dextran sodium sulfate (DSS) model, belong to the most commonly used IBD animal models $(5,6)$. Importantly, when $A p c^{\mathrm{Min} /+}$ mice, which harbor a germline mutation in the $A p c$ gene, are exposed to DSS, colitis markedly accelerates the development of dysplasia and cancer in the colon of $A p c^{\mathrm{Min} /+}$ mice (7). Therefore, it is now regarded that DSS-treated $A p c^{\mathrm{Min} /+}$ mouse is one of rodent models for inflammation-related colorectal tumorigenesis.

Epidemiological studies and experimental evidence have suggested a potential relationship between components of the diet and several diseases, including IBD and cancer (8-10). A large number of experimental studies have shown that high intake of dietary fiber, vegetables, fruits decreases the incidence of colorectal cancer (11). Fermented brown rice and rice bran (FBRA) is a processed food prepared by fermented the brown rice and rice bran with Aspergillus oryzae. In our previous studies, FBRA showed chemopreventive effect against various types of chemically-induced cancer, including colon (12), stomach (13), bladder (14) and esophagus (15) in rodent models. In addition, FBRA has a suppressive effect on 
the acute colitis in rats administered DSS (16). In the present study, we examined the chemopreventive activity of FBRA on colon tumorigenesis in $A p c^{\mathrm{Min} /+}$ mice, a genetic model for colon carcinogenesis, as well as inflammation-related colorectal carcinogenesis using $A p c^{\mathrm{Min} /+}$ mice administered DSS.

\section{Materials and methods}

Animals. The $A p c^{\mathrm{Min} /+}$ mice were purchased from the Jackson Laboratory (Bar Harbor, ME). The $A p c^{\mathrm{Min} /+}$ pedigree was maintained by mating C57BL/6J females with $A p c^{\mathrm{Min} /+}$ males. The $A p c^{\mathrm{Min} /+}$ mice were identified by allele-specific PCR on DNA isolated from the mouse tail. Male C57BL/6J mice (4 weeks of age) were purchased from SLC (Hamamatsu, Japan). All mice were maintained under specific pathogen-free conditions with isolated ventilation cages in an air-conditioned room with a 12:12 L:D cycle, with free access to water and were bred and maintained on a basal diet, CE-2 (CLEA Japan Inc., Tokyo, Japan).

Chemicals. Powdered CE-2 diet was used as the basal diet throughout the study. The experimental diets were prepared by mixing 5.0 and $10.0 \%$ FBRA with CE-2 diet. FBRA was supplied by Genmai Koso Co., Ltd. (Sapporo, Japan). Briefly, the manufacturing process of FBRA was: fermentation base was made by steaming of brown rice and rice bran. Aspergillus oryzae was then seeded to the fermentation base and fermentation process was continued for 18-24 h. Subsequently, second fermentation was continued for additional $12-24 \mathrm{~h}$ for aging purpose. Fermented product was then dried and powdered. Dextran sodium sulfate (DSS) with a molecular weight of 36,000-50,000 was purchased from MP Biomedicals, LLC.

Experimental procedure. The experimental design was approved by the Institutional Ethics Review Committee for animal experiments at Gifu University.

Experiment 1. The $A p c^{\mathrm{Min} /+}$ mice (5 weeks of age) were divided into 3 groups (G1, G2 and G3). The $A p c^{+/+}$littermates (5 weeks of age) were also divided into 3 groups (G4, G5 and G6) as shown in Fig. 1. Mice in groups 1 and 4 were maintained on control diet (CE-2), groups 2 and 5 were fed with 5\% FBRA in diet, and groups 3 and 6 were fed with 10\% FBRA in diet. All mice were sacrificed at 20 weeks of age.

Experiment 2. As shown in Fig. 2, the $A p c^{\mathrm{Min} /+}$ mice (4 weeks of age) were divided into 3 groups (G1, G2 and G3). The $\mathrm{Apc}^{+/+}$littermates (4 weeks of age) were also divided into 3 groups (G4, G5 and G6). Mice in groups 1 and 4 were maintained on control diet (CE-2), groups 2 and 5 were fed with 5\% FBRA, and groups 3 and 6 were fed with 10\% FBRA in control diet. All groups of mice were given $2 \%(w / v)$ DSS in drinking water for 1 week, starting at 5 weeks of age. Mice were sacrificed at 12 weeks of age.

Experiment 3. Male C57BL/6J mice at 4 weeks of age were divided into 4 groups (Fig. 3). Mice in groups 1 and 3 received control diet (CE-2), and the mice in groups 2 and 4 received $10 \%$ FBRA in diet. At 5 weeks of age, the mice in groups 1 and 2 were given $1.5 \%(\mathrm{w} / \mathrm{v})$ DSS in drinking water for 1 week. All surviving mice were sacrificed at 7 weeks of age. The most distal part of the colon $(1 \mathrm{~cm}$ in length) was

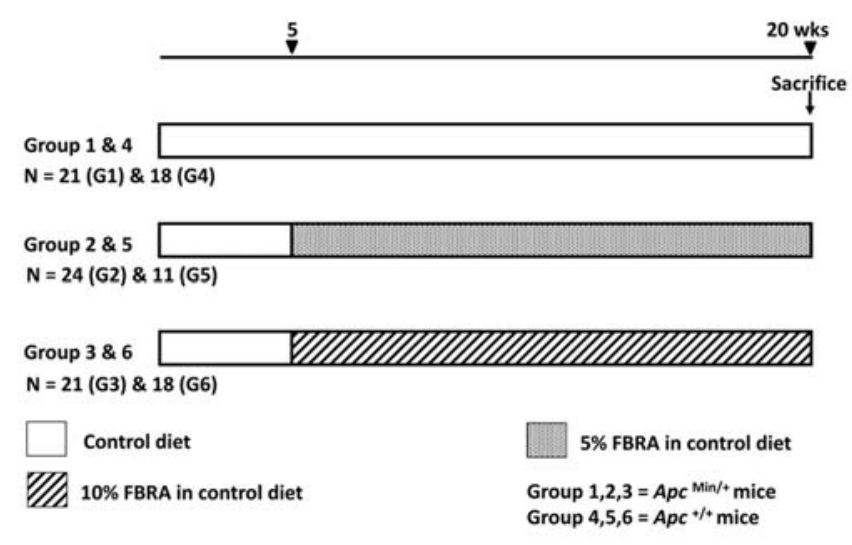

Figure 1. The experimental design to study the chemopreventive effect of the fermented brown rice and rice bran (FBRA) on colorectal tumorigenesis in $A p c^{\mathrm{Min} /+}$ and $A p c^{+/+}$mice (Experiment 1).

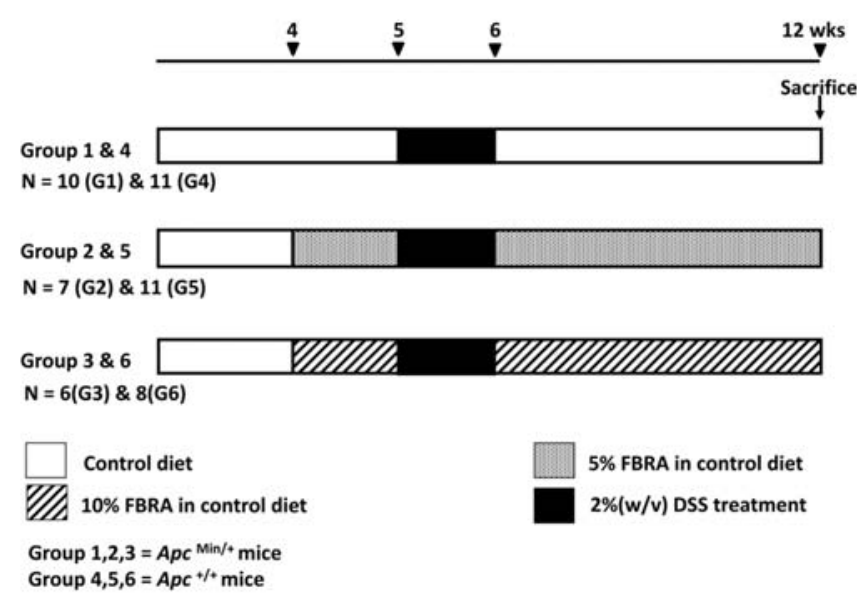

Figure 2. The experimental design to study the chemopreventive effect of the fermented brown rice and rice bran (FBRA) on inflammationrelated colorectal tumorigenesis in DSS-treated $\mathrm{Apc}^{\mathrm{Min} /+}$ and $\mathrm{Apc}^{+/+}$mice (Experiment 2).

dissected and embedded in paraffin for immunohistochemical analysis. The next distal part of colon (2 cm in length) was used for RNA isolation to examine the expression of $i N o s$, Cox2 and Tnfa by quantitative RT-PCR.

Tissue processing. At sacrifice, all mice in Experiment 1 and 2 were measured the final body weight. Liver weight and kidney weight of all mice were measured and the histological analysis was performed to evaluate the toxicity of the FBRA administration. The colons were flushed with PBS, and excised. After the length of large bowel was measured (from the ileocecal junction to the anal verge), they were cut open along the longitudinal axis, and then washed with PBS. The colon was fixed in $10 \%$ buffered formalin for $24 \mathrm{~h}$. To identify colonic tumors, the colons were dripped into a $0.2 \%$ methylene blue solution for $30 \mathrm{sec}$, washed in saline, and then counted by using a light microscope at a magnification of $x 40$.

RNA isolation and cDNA synthesis. RNA was extracted from the colonic tissue by using TRIzol reagent (Invitrogen, Life Technologies, Carlsbad, CA, USA) and an RNeasy mini kit 


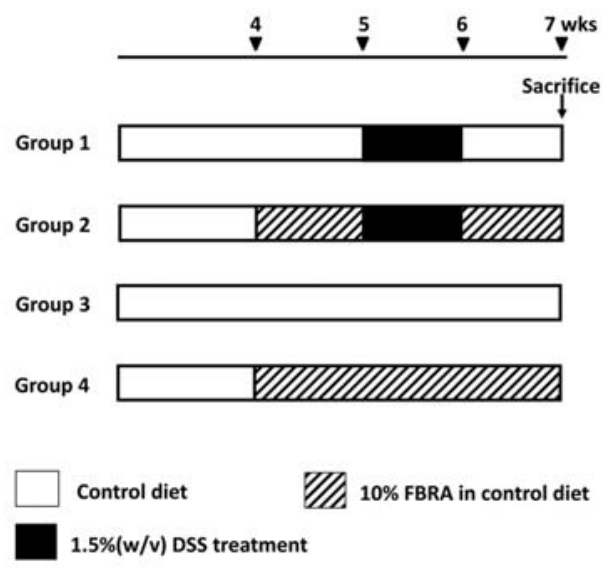

Figure 3. The experimental design to study the effect of the fermented brown rice and rice bran (FBRA) on the mRNA expression levels of iNos, Cox2, and Tnfo in DSS-treated and -untreated $\mathrm{Apc}^{+/+}$mice (Experiment 3 ).

(Qiagen Corp., Hilden, Germany) according to the manufacturers' instructions. The amount and quality of RNA for each sample were assessed with the NanoDrop ${ }^{\circledR}$ ND-1000 UV-Vis spectrophotometer (NanoDrop Technologies, Wilmington, DE, USA). Purified total RNA was reverse-transcribed using the SuperScript First-Strand synthesis system for the reverse transcriptase-polymerase chain reaction (RT-PCR) kit (Invitrogen, Carlsbad, CA), according to the manufacturer's protocol.

Real-time quantitative PCR (RT-PCR). Expression levels of iNos, Cox2, Tnfa and $\beta$-actin mRNA were measured using a Light-Cycler (Roche Applied Science) and the specific sense and antisense primers. The reaction mixture contained $10.0 \mu \mathrm{l}$ of Takara SYBR Premix Ex Taq (Takara Bio Inc.), $1.0 \mu \mathrm{l}$ of $10 \mu \mathrm{M}$ of each primer, $3.0 \mu \mathrm{l}$ of distilled water and $5.0 \mu \mathrm{l}$ of specific cDNA. Oligonucleotide primers were: iNos, 5'-GTT CTCAGCCCAACAATACAAGA-3' and 5'-GTGGACGG GTCGATGTCAC-3'; Cox2, 5'-GCCAGGCTGAACTTCG AAACA-3' and 5'-GCTCACGAGGCCACTGATACCT-3'; Tnf $\alpha, 5$ '-CCCTCACACTCAGATCATCTTCT-3' and 5'-GCT ACGACGTGGGCTACAG-3'; $\beta$-actin, 5'-CATCCGTAAA GACCTCTATGCCAAC-3' and 5'-ATGGAGCCACCGAT CCACA-3'.

Immunohistochemical staining. The avidin-biotin peroxidase complex $(\mathrm{ABC})$ technique was used for immunohistochemical studies. The paraffined sections were deparaffinized, rehydrated in PBS. Then, placed in $10 \mathrm{mmol} / \mathrm{l}$ citrate buffer ( $\mathrm{pH}$ 6.0), and heated in a Pascal pressure cooker (Dako) programmed for $1 \mathrm{~min}$ at $120^{\circ} \mathrm{C}$ for pretreatment. The endogenous peroxidase activity was blocked by incubation for $20 \mathrm{~min}$ in $0.3 \% \mathrm{H}_{2} \mathrm{O}_{2}$. After washing 3 times with PBS, the sections were preincubated with a normal blocking serum for $30 \mathrm{~min}$ at room temperature and then incubated with primary antibodies, which are specific for Ki67 (TEC-3, 1:100 dilution, Dako), overnight at $4^{\circ} \mathrm{C}$. Subsequently, the sections were incubated with biotinylated secondary antibodies (1:250 dilution, KPL) for $30 \mathrm{~min}$ at room temperature, followed by incubation with avidin-coupled peroxidase (Vectastain ${ }^{\circledR}$ Elite $\mathrm{ABC}$ kit) for $30 \mathrm{~min}$ at room temperature. The sections were developed with 3,3V-diaminobenzidine (DAB), counterstained with hematoxylin and mounted coverslips.

Statistical analysis. The data for liver weights, kidney weights, final body weights, tumor incidences and multiplicities, sizes of tumor, lengths of large bowel were analyzed by the Student's

Table I. The liver weights, kidney weights, final body weights, and the length of large bowel.

\begin{tabular}{|c|c|c|c|c|c|c|c|}
\hline \multirow[b]{2}{*}{ Group } & \multirow[b]{2}{*}{ Genotype } & \multirow[b]{2}{*}{ Treatment } & \multirow[b]{2}{*}{ No. ${ }^{b}$} & \multicolumn{3}{|c|}{ Weight $(g)^{\mathrm{a}}$} & \multirow{2}{*}{$\begin{array}{l}\text { Length of large } \\
\text { bowel }(\mathrm{cm})\end{array}$} \\
\hline & & & & Body & Liver & Kidney & \\
\hline \multicolumn{8}{|c|}{ Experiment 1} \\
\hline 1 & $A p c^{\mathrm{Min} /+}$ & Control diet & 21 & $25.2 \pm 3.6$ & $1.41 \pm 0.31$ & $0.30 \pm 0.08$ & $\mathrm{ND}^{\mathrm{c}}$ \\
\hline 2 & $A p c^{\mathrm{Min} /+}$ & $5 \%$ FBRA & 24 & $22.6 \pm 2.2^{\mathrm{d}}$ & $1.36 \pm 0.30$ & $0.30 \pm 0.05$ & ND \\
\hline 3 & $A p c^{\mathrm{Min} /+}$ & $10 \%$ FBRA & 21 & $26.7 \pm 3.0$ & $1.67 \pm 0.31^{\mathrm{e}}$ & $0.33 \pm 0.08$ & ND \\
\hline 4 & $A p c^{+/+}$ & Control diet & 18 & $27.3 \pm 6.1$ & $1.21 \pm 0.34$ & $0.33 \pm 0.12$ & ND \\
\hline 5 & $A p c^{+/+}$ & $5 \%$ FBRA & 11 & $27.8 \pm 4.4$ & $1.23 \pm 0.19$ & $0.33 \pm 0.06$ & ND \\
\hline 6 & $A p c^{+/+}$ & $10 \%$ FBRA & 18 & $28.8 \pm 3.9$ & $1.30 \pm 0.26$ & $0.34 \pm 0.13$ & ND \\
\hline \multicolumn{8}{|c|}{ Experiment 2} \\
\hline 1 & $A p c^{\mathrm{Min} /+}$ & Control diet + DSS & 10 & $21.6 \pm 2.7$ & $1.17 \pm 0.16$ & $0.30 \pm 0.03$ & $12.5 \pm 0.6$ \\
\hline 2 & $A p c^{\mathrm{Min} /+}$ & $5 \%$ FBRA + DSS & 7 & $21.1 \pm 3.3$ & $1.13 \pm 0.23$ & $0.31 \pm 0.06$ & $12.4 \pm 0.8$ \\
\hline 3 & $A p c^{\mathrm{Min} /+}$ & $10 \%$ FBRA + DSS & 6 & $20.2 \pm 3.8$ & $1.04 \pm 0.21$ & $0.29 \pm 0.05$ & $12.8 \pm 1.0$ \\
\hline 4 & $A p c^{+/+}$ & Control diet + DSS & 11 & $24.6 \pm 4.8$ & $1.19 \pm 0.29$ & $0.35 \pm 0.06$ & $12.9 \pm 0.9$ \\
\hline 5 & $A p c^{+/+}$ & $5 \%$ FBRA + DSS & 11 & $25.5+3.1$ & $1.38 \pm 0.24$ & $0.38 \pm 0.07$ & $13.0 \pm 0.7$ \\
\hline 6 & $A p c^{+/+}$ & $10 \%$ FBRA + DSS & 8 & $26.2 \pm 3.6$ & $1.35 \pm 0.37$ & $0.40 \pm 0.03^{\mathrm{f}}$ & $13.7 \pm 0.7$ \\
\hline
\end{tabular}

${ }^{\mathrm{a}}$ Means $\pm \mathrm{SD}$; ${ }^{b}$ number of examined mice; ${ }^{\mathrm{N} D}$, not determined. ${ }^{\mathrm{d}}$ Significantly different from group 1 by Student's t-test ( $\left.\mathrm{p}<0.005\right)$.

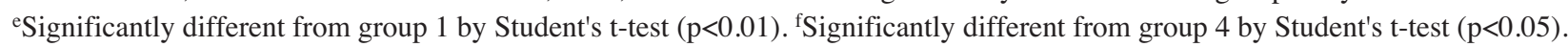


Table II. The incidences, multiplicities and sizes of the tumors.

\begin{tabular}{|c|c|c|c|c|c|c|}
\hline Group & Genotype & Treatment & No. ${ }^{a}$ & Incidence $(\%)^{\mathrm{b}}$ & Multiplicityc & Tumor size \\
\hline \multicolumn{7}{|c|}{ Experiment 1} \\
\hline 1 & $A p c^{\mathrm{Min} /+}$ & Control diet & 21 & $19 / 21(90)$ & $2.9 \pm 1.8$ & $18.1 \pm 20.9$ \\
\hline 2 & $A p c^{\mathrm{Min} /+}$ & $5 \%$ FBRA & 24 & $20 / 24(83)$ & $2.3 \pm 1.9$ & $17.3 \pm 18.8$ \\
\hline 3 & $A p c^{\mathrm{Min} /+}$ & $10 \%$ FBRA & 21 & $20 / 21(95)$ & $2.5 \pm 1.7$ & $21.6 \pm 23.9$ \\
\hline 4 & $A p c^{+/+}$ & Control diet & 18 & $0 / 18(0)$ & $0.0 \pm 0.0$ & $\mathrm{ND}^{\mathrm{e}}$ \\
\hline 5 & $A p c^{+/+}$ & $5 \%$ FBRA & 11 & $0 / 11(0)$ & $0.0 \pm 0.0$ & ND \\
\hline 6 & $A p c^{+/+}$ & $10 \%$ FBRA & 18 & $0 / 18(0)$ & $0.0 \pm 0.0$ & ND \\
\hline \multicolumn{7}{|c|}{ Experiment 2} \\
\hline 1 & $A p c^{\mathrm{Min} /+}$ & Control diet + DSS & 10 & $10 / 10(100)$ & $20.5 \pm 6.9$ & $5.1 \pm 7.5$ \\
\hline 2 & $A p c^{\mathrm{Min} /+}$ & $5 \%$ FBRA + DSS & 7 & $7 / 7(100)$ & $11.3 \pm 5.6^{\mathrm{f}}$ & $5.1 \pm 5.9$ \\
\hline 3 & $A p c^{\mathrm{Min} /+}$ & $10 \%$ FBRA + DSS & 6 & $6 / 6(100)$ & $9.7 \pm 4.8^{\mathrm{g}}$ & $3.3 \pm 3.6$ \\
\hline 4 & $A p c^{+/+}$ & Control diet + DSS & 11 & $0 / 11(0)$ & $0.0 \pm 0.0$ & ND \\
\hline 5 & $A p c^{+/+}$ & $5 \%$ FBRA + DSS & 11 & $0 / 11(0)$ & $0.0 \pm 0.0$ & ND \\
\hline 6 & $A p c^{+/+}$ & $10 \%$ FBRA + DSS & 8 & $0 / 8(0)$ & $0.0 \pm 0.0$ & ND \\
\hline
\end{tabular}

${ }^{\mathrm{a}}$ Number of examined mice; ${ }^{\mathrm{b}}$ number of mice observed each lesion (\%); ${ }^{\mathrm{c}}$ number of total tumor per mouse (Mean \pm SD). ${ }^{\mathrm{d}} \mathrm{Means} \pm \mathrm{SD}$ of the sizes of colonic tumor $\left(\mathrm{mm}^{3}\right)$; ${ }^{\mathrm{e}} \mathrm{ND}$, not determined. ${ }^{\mathrm{f}}$ Significantly different from group 1 by Student's t-test $(\mathrm{p}<0.02)$. ${ }^{\mathrm{g}}$ Significantly different from group 1 by Student's t-test $(\mathrm{p}<0.005)$.

Table III. The effect of FBRA on the mRNA expression levels of Cox2, iNos, and Tnfa in the colonic mucosa.

\begin{tabular}{|c|c|c|c|c|c|c|}
\hline \multirow[b]{2}{*}{ Group } & \multirow[b]{2}{*}{ Genotype } & \multirow[b]{2}{*}{ Treatment } & \multirow[b]{2}{*}{ No. ${ }^{b}$} & \multicolumn{3}{|c|}{ Ratio of targeted mRNA/ß-actin mRNA } \\
\hline & & & & $\operatorname{Cox} 2$ & $i N o s$ & $\operatorname{Tnfa}$ \\
\hline \multicolumn{7}{|c|}{ Experiment 3} \\
\hline 1 & $A p c^{+/+}$ & Control diet + DSS & 6 & $1.840 \pm 1.092$ & $0.581 \pm 0.437$ & $0.954 \pm 0.363$ \\
\hline 2 & $A p c^{+/+}$ & $10 \%$ FBRA + DSS & 4 & $0.384 \pm 0.365^{\mathrm{c}}$ & $0.032 \pm 0.046^{\mathrm{d}}$ & $0.520 \pm 0.324$ \\
\hline 3 & $A p c^{+/+}$ & Control diet & 4 & $0.134 \pm 0.173^{\mathrm{e}}$ & $3.450 \times 10-6 \pm 1.879 \times 10^{-6 \mathrm{e}}$ & $2.833 \times 10-8 \pm 5.179 \times 10^{-8 \mathrm{e}}$ \\
\hline 4 & $A p c^{+/+}$ & $10 \%$ FBRA & 4 & $0.007 \pm 0.005^{\mathrm{f}}$ & $3.412 \times 10-6 \pm 5.910 \times 10^{-7 f}$ & $7.880 \times 10-9 \pm 7.349 \times 10^{-9 \mathrm{f}}$ \\
\hline
\end{tabular}

${ }^{\mathrm{a}}$ Means $\pm \mathrm{SD}$; ${ }^{\mathrm{b}}$ number of examined mice. ${ }^{\mathrm{c}}$ Significantly different from group 1 by Student's t-test $(\mathrm{p}<0.04)$. ${ }^{\mathrm{d}}$ Significantly different from

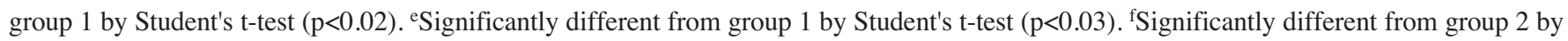
Student's t-test $(\mathrm{p}<0.03)$.

t-test. The Ki67 positive cell index was analyzed by the Welch's t-test. Expression levels for iNos, Cox2, and Tnfa mRNA were analyzed by the Mann-Whitney U test.

\section{Results}

Administration of FBRA had no effect on colonic tumorigenesis in Apc $\mathrm{Min/+}^{\mathrm{m}}$ mice. In Experiment 1, we examined the effects of FBRA administration on the development of colorectal tumors in $A p c^{\mathrm{Min} /+}$ mouse, a model for FAP. Although there were significant differences in the final body weight between groups 1 and $2(\mathrm{p}<0.005)$ and the liver weight between groups 1 and 3 ( $\mathrm{p}<0.01$ ), no evidence of toxicity was confirmed by the histological analysis as shown in Table I. All mice in groups 1,2, and 3 developed the tumors in the colon but no tumors were found in mice in groups 4,5 , and 6 .
There were no differences in the incidence, multiplicity or size of tumors in colon among the groups 1,2 and 3 as shown in Table II. Additionally, there were no difference in the Ki67 positive index in colon tumors between FBRA-treated and control diet-treated groups in either $A p c^{\mathrm{Min} /+}$ or $A p c^{+/+}$mice (data not shown).

Administration of FBRA inhibited the inflammation-related colorectal tumorigenesis. To examine the effect of FBRA on inflammation-related colorectal tumorigenesis, we fed DSStreated $A p c^{\mathrm{Min} /+}$ mice with FBRA and examined the development of colon tumors in Experiment 2. During 8 weeks of experimental period, about one-third of total mice, which were exposed to DSS, in groups 1,2 and 3 died because of severe colitis due to DSS treatment. However, there was no significant difference in the surviving rate among groups 1, 2 
Cell proliferative index (Ki67)

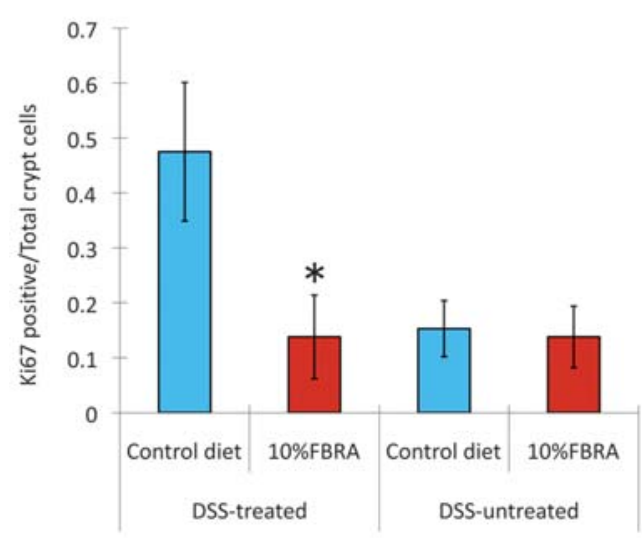

Figure 4. Administration of $10 \%$ FBRA in DSS-treated $A p c^{+/+}$mice significantly decreased the cell proliferative index (Ki67) in comparison with control diet group but had no effect in DSS-untreated $\mathrm{Apc}^{+/+}$mice. ${ }^{*}$ Significantly different from control diet group by Welch's t-test $(\mathrm{p}<0.001)$.

and 3. Additionally, there were no differences in the final body weight, the weight of liver, and in the length of large bowel among the groups at the time of sacrifice, but there was a significant difference in the weight of kidney between group 4 and $6(\mathrm{p}<0.05)$ as shown in Table I.

In this experiment, all mice in groups 1,2, and 3 developed tumors in the colon, but no colonic tumor was found in mice in groups 4, 5, and 6. Administration of 5\% FBRA (group 2) and $10 \%$ FBRA (group 3) significantly suppressed the multiplicity of total tumors in the colon in comparison with group 1 ( $\mathrm{p}<0.02$ and $\mathrm{p}<0.005$, respectively). However, there was no significant difference in the size of colonic tumors between FBRA-treated groups (groups 2 and 3) and control diet group (group 1) as shown in Table II.

FBRA significantly decreased the mRNA expression levels of Cox 2 and iNos. In order to investigate the molecular mechanisms of the suppressing effect of FBRA against inflammation-related colorectal tumorigenesis in DSS-treated mice, we fed DSS-treated and DSS-untreated $\mathrm{Apc}^{+/+}$mice with $10 \%$ FBRA, and examined the mRNA expression levels of the inflammation-related genes, Cox2, iNos, and Tnfa in Experiment 3 . The DSS treatment significantly increased the expression levels of Cox2, iNos, and Tnfa in colonic mucosa $(\mathrm{p}<0.03)$ as shown in Fig. 3. Importantly, administration of $10 \%$ FBRA significantly suppressed the mRNA expression levels of Cox2 (group 2; 0.384 \pm 0.365 , vs. group1; $1.840 \pm 1.092$, $\mathrm{p}<0.04$ ) and $i N o s$ (group 2;0.032 \pm 0.046 , vs. group 1; $0.581 \pm 0.437, \mathrm{p}<0.02)$. In contrast, no significant difference was detected in the expression level of Tnfa (group 2; $0.520 \pm 0.324$, vs. group $1 ; 0.954 \pm 0.363$ ) in comparison with control diet group (Table III).

Administration of FBRA significantly decreased the cell proliferative index in DSS-treated Apc $\mathrm{Min/+}^{+}$and $\mathrm{Apc}^{+/+}$mice. To further examine the cell kinetics of colonic crypt cells in DSStreated and DSS-untreated mice, we performed immunohistochemical analyses for the expression of Ki67, a marker for cell proliferation using the colon sections from the mice in Experiment 3. FBRA administration in DSS-treated mice significantly decreased the Ki67 positive cell index in com-

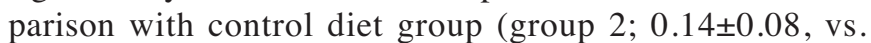
group $1 ; 0.48 \pm 0.13$ ) but had no effect on cell proliferative index in DSS-untreated mice (group $4 ; 0.14 \pm 0.06$, vs. group 3; $0.15 \pm 0.05$ ) as shown in Fig. 4, suggesting that suppressive effects of FBRA on cell proliferation is closely associated with colitis.

\section{Discussion}

Several studies indicate that dietary factors play an important role in the pathogenesis of inflammatory bowel disease and colorectal cancer $(8,9,11,12,17-19)$. A number of studies have shown the chemopreventive effect of fermented brown rice and rice bran (FBRA) on several types of cancer, including colon cancer (12-15). In contrast to previous findings that FBRA significantly suppressed azoxymethane-induced colorectal carcinogenesis in rats, in the present study, FBRA has no effect on the tumor development of the colon in $\mathrm{Apc}^{\mathrm{Min} /+}$ mice, a hereditary carcinogenesis model of the colon. The results indicate that the suppressive effects of FBRA on colorectal carcinogenesis are different depending on models for colon cancer. It is noteworthy that the administration of FBRA significantly suppressed the total number of colonic tumors in DSS-treated $A p c^{\mathrm{Min} /+}$ mice. The results clearly indicate that FBRA specifically inhibits inflammatory-related colorectal carcinogenesis in $A p c^{\mathrm{Min} /+}$ genetic background. Given the previous findings by Kataoka et al (16) in which FBRA suppresses DSS-induced inflammation in the colon, the mode of chemopreventive action of FBRA may be attributable to be the anti-inflammatory activity. Consistent with the hypo-thesis, administration of FBRA prevented the shortening of large bowel of DSS-treated $A p c^{\mathrm{Min} /+}$ mice, one of the biological parameter of severity of colonic inflammation.

Generally, hyperproliferation is suggested to be relevant to carcinogenesis of many organs (20-22). Therefore, the control of cell proliferation in the target organs is regarded as an important strategy for chemoprevention. A number of compounds consisting FBRA revealed chemopreventive actions that are accompanied by the decreased proliferative activities in the target organs. It is important to note that the administration of FBRA significantly decreased the Ki67 positive cell index in colonic crypts of DSS-treated mice, whereas such effects were not observed in colonic crypts of non-treated control mice. Thus, the suppressive effect on cellular proliferation in tumor cells might be one of the important mechanisms of the chemopreventive effects of FBRA.

Nitric oxide (NO) is involved in many of the pathophysiological processes that lead to colon cancer development and progression. The role of NO in carcinogenesis is not well defined and appears to be complex due to divergent functional activities under normal and pathophysiological conditions (23-25). It is probable that the high sustained levels of NO generated by iNos, the inducible and $\mathrm{Ca}^{2+}$-independent isoform of NOs, can produce multiple types of damage and lead to an accumulation of gene mutations that contribute to malignant transformation $(25,26)$. Evidence from both in vitro and in vivo 
experiments support that $\mathrm{NO}$ and its reactive metabolite peroxynitrite stimulate Cox 2 activity leading generation of tumor growth enhancing prostaglandins and influence colon tumorigenesis (27-29). Herein we showed that the expression levels of iNos and Cox2 were strongly increased in the colonic tissues of mice treated with DSS in comparison with the untreated mice, suggesting that the increased expressions of iNos and Cox2 are involved in the DSS-induced inflammation. It is important that the administration of FBRA significantly decreased the mRNA expression levels of both iNos and Cox2 in the colon tissues of mice in comparison with the control mice.

FBRA is a processed food prepared by fermenting brown rice and rice bran with Aspergillus oryzae. The nutritional and sanitary advantage of fermentation has been recognized, although the details are not well known. Fermented soy bean paste or soy sauce, which prepared by fermenting with Aspergillus oryzae, has been found to be more stable against lipid peroxidation than unfermented soybeans, because Aspergillus oryzae-fermented soybean products contain several antioxidants such as 6-hydroxydaidzein, 8-hydroxydaidzein and 8-hydroxygenistein more abundantly than unfermented soybeans (30). These 8-hydroxyisiflavones are reported to possess greater 1,1-diphenyl-2-picrylhydrazyl (DPPH) radicalscavenging activity and antiproliferative activity than the corresponding isoflavone analogs $(30,31)$. Furthermore, these 8-hydroxyisoflavones and 6-hydroxydaidzein showed high antimutagenic activity $(31,32)$. Several epidemiological and preclinical studies suggested the chemopreventive effects of such fermented soybean products (33-35). Dihydroferulic acid and dihydrosinapic acid, which were isolated from unpolished rice vinegar (Kurosu), were suggested as the major constituents responsible for radical scavenging activity of Kurosu (36). These acids are produced in Kurosu through the process of the fermentation from ferulic acid and sinapic acid. Rice bran contains $\sim 20 \%$ oil which contains several bioactive polyphenols including ferulic acid, protocatechuic acid, sinapic acid, and vanillic acid (37). Thus, it is possible that FBRA has similar mechanistic aspects to the fermented soybeans or Kurosu.

In conclusion, we demonstrated that the administration of FBRA inhibits inflammation-related colorectal tumorigenesis induced by DSS in $A p c^{\mathrm{Min} /+}$ mice. Our results also suggest that a reduction of Cox 2 and iNos mRNA expression levels and a suppression of cell proliferative activity in colonic epithelium may be involved in such chemopreventive effects of FBRA.

\section{Acknowledgements}

We would like to thank Kyoko Takahashi and Ayako Suga for technical assistance, and Yoshitaka Kinjo for animal care. This work was supported by a Grant-in-Aid from the Ministry of Education, Culture, Sports, Science and Technology and Grant-in-Aid from the Ministry of Health, Labour and Welfare of Japan. Suphot Phutthaphadoong is a Ph.D. student under the Royal Golden Jubilee Ph.D. Program of Thailand.

\section{References}

1. Bernstein CN, Blanchard JF, Kliewer E and Wajda A: Cancer risk in patients with inflammatory bowel disease: a populationbased study. Cancer 91: 854-862, 2001.
2. Xie $\mathrm{J}$ and Itzkowitz SH: Cancer in inflammatory bowel disease. World J Gastroenterol 14: 378-389, 2008.

3. Zisman TL and Rubin DT: Colorectal cancer and dysplasia in inflammatory bowel disease. World J Gastroenterol 14: 2662-2669, 2008.

4. Itzkowitz SH and Yio X: Inflammation and cancer IV. Colorectal cancer in inflammatory bowel disease: the role of inflammation. Am J Physiol Gastrointest Liver Physiol 287: G7-G17, 2004.

5. Wirtz S, Neufert C, Weigmann B and Neurath MF: Chemically induced mouse models of intestinal inflammation. Nat Protoc 2 : 541-546, 2007.

6. Kawada M, Arihiro A and Mizoguchi E: Insights from advances in research of chemically induced experimental models of human inflammatory bowel disease. World J Gastroenterol 13: 5581-5593, 2007.

7. Tanaka T, Kohno H, Suzuki R, et al: Dextran sodium sulfate strongly promotes colorectal carcinogenesis in Apc(Min/+) mice: inflammatory stimuli by dextran sodium sulfate results in development of multiple colonic neoplasms. Int J Cancer 118: 25-34, 2006

8. Campos FG, Logullo Waitzberg AG, Kiss DR, Waitzberg DL, Habr-Gama A and Gama-Rodrigues J: Diet and colorectal cancer: current evidence for etiology and prevention. Nutr Hosp 20: $18-25,2005$.

9. Ryan-Harshman M and Aldoori W: Diet and colorectal cancer: Review of the evidence. Can Fam Physician 53: 1913-1920, 2007.

10. Danese S, Sans M and Fiocchi C: Inflammatory bowel disease: the role of environmental factors. Autoimmun Rev 3: 394-400, 2004.

11. Gonzalez CA: Nutrition and cancer: the current epidemiological evidence. Br J Nutr 96 (Suppl 1): S42-S45, 2006.

12. Kawabata K, Tanaka T, Murakami T, et al: Dietary prevention of azoxymethane-induced colon carcinogenesis with rice-germ in F344 rats. Carcinogenesis 20: 2109-2115, 1999.

13. Tomita H, Kuno T, Yamada Y, et al: Preventive effect of fermented brown rice and rice bran on $\mathrm{N}$-methyl-N'-nitro-Nnitrosoguanidine-induced gastric carcinogenesis in rats. Oncol Rep 19: 11-15, 2008.

14. Kuno T, Hirose Y, Yamada Y, et al: Chemoprevention of mouse urinary bladder carcinogenesis by fermented brown rice and rice bran. Oncol Rep 15: 533-538, 2006.

15. Kuno T, Hirose Y, Hata K, et al: Preventive effect of fermented brown rice and rice bran on $\mathrm{N}$-nitrosomethylbenzylamine-induced esophageal tumorigenesis in rats. Int J Oncol 25: 1809-1815, 2004.

16. Kataoka K, Ogasa S, Kuwahara T, et al: Inhibitory effects of fermented brown rice on induction of acute colitis by dextran sulfate sodium in rats. Dig Dis Sci 53: 1601-1608, 2008.

17. Seril DN, Liao J, Ho KL, Warsi A, Yang CS and Yang GY: Dietary iron supplementation enhances DSS-induced colitis and associated colorectal carcinoma development in mice. Dig Dis Sci 47: 1266-1278, 2002.

18. Murakami A, Hayashi R, Tanaka T, Kwon KH, Ohigashi H and Safitri R: Suppression of dextran sodium sulfate-induced colitis in mice by zerumbone, a subtropical ginger sesquiterpene, and nimesulide: separately and in combination. Biochem Pharmacol 66: 1253-1261, 2003.

19. Carrier J, Medline A, Sohn KJ, Choi M, Martin R, Hwang SW and Kim YI: Effects of dietary folate on ulcerative colitisassociated colorectal carcinogenesis in the interleukin 2- and beta(2)-microglobulin-deficient mice. Cancer Epidemiol Biomarkers Prev 12: 1262-1267, 2003.

20. Bacchi CE and Gown AM: Detection of cell proliferation in tissue sections. Braz J Med Biol Res 26: 677-687, 1993.

21. Rindi G, D'Adda T, Froio E, Fellegara G and Bordi C: Prognostic factors in gastrointestinal endocrine tumors. Endocr Pathol 18: 145-149, 2007.

22. van Diest PJ, van der Wall E and Baak JP: Prognostic value of proliferation in invasive breast cancer: a review. J Clin Pathol 57: 675-681, 2004.

23. Kroncke KD, Fehsel K and Kolb-Bachofen V: Inducible nitric oxide synthase in human diseases. Clin Exp Immunol 113: 147-156, 1998.

24. Alderton WK, Cooper CE and Knowles RG: Nitric oxide synthases: structure, function and inhibition. Biochem J 357 : 593-615, 2001.

25. Rao CV: Nitric oxide signaling in colon cancer chemoprevention. Mutat Res 555: 107-119, 2004. 
26. Forrester K, Ambs S, Lupold SE, et al: Nitric oxide-induced p53 accumulation and regulation of inducible nitric oxide synthase expression by wild-type p53. Proc Natl Acad Sci USA 93: 2442-2447, 1996.

27. Salvemini D, Misko TP, Masferrer JL, Seibert K, Currie MG and Needleman P: Nitric oxide activates cyclooxygenase enzymes. Proc Natl Acad Sci USA 90: 7240-7244, 1993.

28. Tetsuka T, Daphna-Iken D, Miller BW, Guan Z, Baier LD and Morrison AR: Nitric oxide amplifies interleukin 1-induced cyclooxygenase-2 expression in rat mesangial cells. J Clin Invest 97: 2051-2056, 1996.

29. Marnett LJ, Wright TL, Crews BC, Tannenbaum SR and Morrow JD: Regulation of prostaglandin biosynthesis by nitric oxide is revealed by targeted deletion of inducible nitric-oxide synthase. J Biol Chem 275: 13427-13430, 2000.

30. Esaki H, Kawakishi S, Morimitsu Y and Osawa T: New potent antioxidative o-dihydroxyisoflavones in fermented Japanese soybean products. Biosci Biotechnol Biochem 63: 1637-1639, 1999.

31. Hirota A, Taki S, Kawaii S, Yano M and Abe N: 1,1-Diphenyl2-picrylhydrazyl radical-scavenging compounds from soybean miso and antiproliferative activity of isoflavones from soybean miso toward the cancer cell lines. Biosci Biotechnol Biochem 64: 1038-1040, 2000.

32. Chen YC, Inaba M, Abe $\mathrm{N}$ and Hirota A: Antimutagenic activity of 8-hydroxyisoflavones and 6-hydroxydaidzein from soybean miso. Biosci Biotechnol Biochem 67: 903-906, 2003.
33. Zhou JR, Yu L, Zhong Y and Blackburn GL: Soy phytochemicals and tea bioactive components synergistically inhibit androgen-sensitive human prostate tumors in mice. J Nutr 133: 516-521, 2003.

34. Ohta T, Nakatsugi $\mathrm{S}$, Watanabe $\mathrm{K}$, et al: Inhibitory effects of Bifidobacterium-fermented soy milk on 2-amino-1-methyl-6phenylimidazo[4,5-b]pyridine-induced rat mammary carcinogenesis, with a partial contribution of its component isoflavones. Carcinogenesis 21: 937-941, 2000.

35. Fukutake M, Takahashi M, Ishida K, Kawamura H, Sugimura T and Wakabayashi K: Quantification of genistein and genistin in soybeans and soybean products. Food Chem Toxicol 34: 457-461, 1996.

36. Shimoji Y, Tamura Y, Nakamura Y, et al: Isolation and identification of DPPH radical scavenging compounds in Kurosu (Japanese unpolished rice vinegar). J Agric Food Chem 50: 6501-6503, 2002.

37. Hudson EA, Dinh PA, Kokubun T, Simmonds MS and Gescher A: Characterization of potentially chemopreventive phenols in extracts of brown rice that inhibit the growth of human breast and colon cancer cells. Cancer Epidemiol Biomarkers Prev 9: $1163-1170,2000$. 